\title{
Chiral Heterocyclic Ligands. X. Synthesis and Metal Complexes of Hindered and Chiral 2,2'-Bipyrimidines.
}

\author{
Alison J. Downard, ${ }^{A}$ Ian G. Phillips, ${ }^{A}$ Peter J. Steel ${ }^{A, B}$ \\ ${ }^{\text {A }}$ Department of Chemistry, University of Canterbury, Private Bag 4800, Christchurch, New \\ Zealand. \\ B Author to whom correspondence should be addressed (Email: peter.steel@canterbury.ac.nz).
}

The first examples of 2,2'-bipyrimidine ligands incorporating bulky or chiral substituents have been prepared by nickel(0)-mediated homo-coupling reactions of chloropyrimidines. The 4,4'-di-(tert-butyl) derivative 2 and the chiral derivative 5, with 4,5-fused bornane groups, have been shown to form mononuclear metal complexes in which they coordinate through the less hindered nitrogen donors. 
Heterocyclic ligands that bridge two metal centres have found numerous applications in coordination, organometallic and metallosupramolecular chemistry. ${ }^{[1-3]}$ Ligands incorporating two 2,2'-bipyridine-like, chelating binding domains have been particularly important. ${ }^{[2]}$ Of such ligands, 2,2'-bipyrimidine $\mathbf{1}$ (Figure 1) occupies a special place, as it positions the metals in close proximity (ca. $5.5 \AA$ separation), thereby facilitating strong metal-metal interactions. ${ }^{[4]}$ This ligand was first prepared over forty years ago by Ullmann coupling of 2bromopyrimidine, albeit in low yield. ${ }^{[5]}$ Recently, two much improved syntheses of $\mathbf{1}$ were reported $^{[6]}$ that are likely to make it an even more popular bridging ligand. Surprisingly few substituted derivatives of 1 have been prepared and used as ligands. ${ }^{[4]}$ 4,4'-Disubstituted derivatives are potentially capable of displaying various metal binding modes; three mononuclear isomers (A-C) and two binuclear isomers (D,E) can be envisaged (Figure 1). To our knowledge, the only such ligand previously described is the 4,4'-dimethyl compound, which was the subject of a cursory study of its complexes with ruthenium(II). ${ }^{[7]}$ We now describe the syntheses and some metal complexes of two new derivatives, one of which contains bulky tert-butyl substituents and the other possesses fused bornane groups and represents the first homochiral derivative.

[Figure 1 here]

The 4,4'-di-(tert-butyl) derivative 2 was prepared, as shown in Scheme 1, by $\mathrm{Ni(0)-}$ mediated homo-coupling of 2-chloro-4-(tert-butyl)pyrimidine. Initial attempts to effect this reaction using a procedure based on that of Nasielski et al., ${ }^{[8]}$ which we have found to be effective for related heteroaryl halides, ${ }^{[9]}$ proved singularly unsuccessful. Coupling was finally achieved using the zinc-mediated procedure pioneered by Iyoda et al., ${ }^{[10]}$ if only in disappointingly low yield. This new ligand was characterized by mass spectrometry and ${ }^{1} \mathrm{H}$ and ${ }^{13} \mathrm{C}$ NMR spectroscopy. Reaction of 2 with one or two equivalents of $\mathrm{Mo}(\mathrm{CO})_{4}\left(\eta^{4}-\right.$ norbornadiene) gave an unstable red complex, which was identified by ${ }^{1} \mathrm{H}$ NMR as the symmetrical mononuclear complex 3.

\section{[Scheme 1 here]}

Reaction of 2 with $\mathrm{Ru}(\mathrm{dmb})_{2} \mathrm{Cl}_{2}$ (dmb = 4,4'-dimethyl-2,2'-bipyridine) gave, in good yield, a red complex 4, which was isolated as a hexafluorophosphate salt. This complex was shown by mass spectrometry to be mononuclear and its ${ }^{1} \mathrm{H}$ and ${ }^{13} \mathrm{C}$ NMR spectra were readily assigned by comparison with the spectra of related complexes. ${ }^{[11]}$ In particular, the symmetrical nature of the complex and the high-field position of the H6,6' proton signal clearly identified the structure as being that of $\mathbf{4}$. The visible absorption spectrum of $\mathbf{4}$ in aectonitrile consists of a combination of a higher energy $d-\pi^{*}(\mathrm{dmb})$ MLCT transition (442 
$\mathrm{nm}$ ) and a lower energy $\mathrm{d}-\pi^{*}(2)$ MLCT shoulder (480 $\left.\mathrm{nm}\right)$. Cyclic voltammetry, in acetonitrile with $0.1 \mathrm{M} \mathrm{Bu}_{4} \mathrm{NPF}_{6}$ supporting electrolyte, displayed a reversible one-electron oxidation $\left(E_{1 / 2}=+1.17 \mathrm{~V}\right.$, versus SCE) of the ruthenium centre, a reversible first reduction attributed to electron transfer into the coordinated ligand $2\left(\mathrm{E}_{1 / 2}=-1.23 \mathrm{~V}\right)$, two successive reversible dmb-based reductions $\left(\mathrm{E}_{1 / 2}=-1.68\right.$ and $\left.-1.90 \mathrm{~V}\right)$ and an irreversible further reduction of the coordinated ligand $2\left(\mathrm{E}_{1 / 2}=-2.11 \mathrm{~V}\right)$. This behaviour is similar to that of related complexes of $\mathbf{1},{ }^{[4,12]}$ but with potentials shifted due to the electron donating nature of the tert-butyl substituents. ${ }^{[13]}$ In both these complexes the ligand 2 coordinates in mode A (Figure 1), employing the less sterically hindered nitrogen donors, distal from the bulky tertbutyl groups. All attempts to enforce coordination to two metal centres proved unsuccessful.

We have previously described the syntheses of many chiral ligands comprised of bornane units fused to heterocyclic rings, such as pyrazole ${ }^{[14,15]}$ and pyrazine. ${ }^{[16]}$ As an extension of this work we have now synthesized the first chiral 2,2'-bipyrimidine 5, as shown in Scheme 2. 3-Formylcamphor 6 was condensed with guanidine carbonate to give the known aminopyrimidine 7 , which was then diazotised in conc. $\mathrm{HCl}$ to give a mixture of the pyrimidinone $\mathbf{8}$ and the chloro derivative $\mathbf{9}$, which were separated by chromatography on silica gel. Additional 9 was obtained from 8 by reaction in refluxing $\mathrm{POCl}_{3}$, as has been previously described. ${ }^{[17]}$ The chloropyrimidine $\mathbf{9}$ was then subjected to nickel-mediated coupling to give $\mathbf{5}$ in moderate yield. This new ligand was characterised by mass spectrometry and ${ }^{1} \mathrm{H}$ and ${ }^{13} \mathrm{C}$ NMR spectra, which were assigned by comparison with the spectra of related chiral ligands containing a fused-bornane group. ${ }^{[14-16,18]}$

[Scheme 2 here]

Reaction of 5 with one equivalent of $\mathrm{PdCl}_{2}$ gave a yellow complex, which was characterised by elemental analysis as $\mathbf{1 0}$ (Scheme 2). Although the complex was found to be insoluble in common NMR solvents, its structure is most likely $\mathbf{1 0}$ given the large size of the camphor substituents. The proposed structure $\mathbf{1 0}$ is supported by that of the monomolybdenum(0) complex 11, which was prepared from reaction of 5 with either one or two equivalents of $\mathrm{Mo}(\mathrm{CO})_{4}\left(\eta^{4}-\mathrm{C}_{7} \mathrm{H}_{8}\right)$. The ${ }^{1} \mathrm{H}$ NMR spectrum of 11 clearly indicated the symmetrical mononuclear structure shown.

The ruthenium(II) complex 12 (Scheme 2) was prepared by reaction of $\mathbf{5}$ with one equivalent of $\mathrm{Ru}(\mathrm{dmb})_{2} \mathrm{Cl}_{2}$ and isolated as a red hexafluorophosphate salt. Analysis by mass spectrometry confirmed that this complex was mononuclear, whilst the symmetrical N1-N1' coordination shown was confirmed by the ${ }^{1} \mathrm{H}$ and ${ }^{13} \mathrm{C}$ NMR spectra, which were straightforwardly assigned by comparison with the spectra of related ligands and 
complexes. ${ }^{[15]}$ In contrast to the complex 4 , in which the $\Delta$ and $\Lambda$ forms of the complex are enantiomeric, the chiral nature of $\mathbf{5}$ means that the $\Delta$ and $\Lambda$ forms of $\mathbf{1 2}$ are diastereoisomeric ${ }^{[19]}$ and therefore distinguished in the ${ }^{1} \mathrm{H}$ NMR spectrum. For example, the $\mathrm{H} 4$ protons of the pyrimidine rings of the two diastereoisomers are observed as two singlets at 7.65 and $7.68 \mathrm{ppm}$. Only the two most upfield singlets could be unambiguously assigned to specific $\Delta$ and $\Lambda$ forms. Inspection of molecular models showed that in the $\Delta$-diastereoisomer the syn-9- $\mathrm{CH}_{3}$ protons $(0.36 \mathrm{ppm})$ are positioned above a pyridine ring of a nearby $\mathrm{dmb}$ ligand and therefore more shielded relative to the $\Lambda$-isomer where the corresponding protons (0.77 ppm) are coplanar with a pyridine ring. The complete assignment of the ${ }^{1} \mathrm{H}$ NMR spectrum of the mixture of diastereoisomers of $\mathbf{1 2}$ would require physical separation of the $\Delta$ and $\Lambda$ forms, ${ }^{[20]}$ which was not attempted.

The complex 12 in acetonitrile exhibits a broad visible absorption band centred around $456 \mathrm{~nm}$, which is probably a combination of MLCT transitions into the ligand $\mathbf{5}$ and the dmb ligands. The cyclic voltammogram of $\mathbf{1 2}$ in acetonitrile comprises a reversible one-electron oxidation $\left(E_{1 / 2}=+1.12 \mathrm{~V}\right.$, versus $\left.\mathrm{SCE}\right)$ and three reversible one-electron reductions $\left(\mathrm{E}_{1 / 2}=\right.$ $1.39,-1.69$ and $-1.92 \mathrm{~V}$ ). Thus, this complex is slightly easier to oxidise than $\mathbf{4}$, but harder to reduce, which reflects the increased electron donating alkyl substitution within the pyrimidine ring.

In conclusion, we have prepared the first examples of 2,2-bipyrimidines with bulky or chiral substituents and shown that they coordinate through mode A (Figure 1), with coordination through the less hindered N-donors. Thus far, all attempts to enforce bridging coordination to two metal centres have proved fruitless. 


\section{Experimental}

\section{General}

For general procedures and instrumentation see ref. 21. 2-Chloro-4-(tert-butyl)pyrimidine, ${ }^{[22]}$ 3-formylcamphor $\quad$ 6, $^{[23]} \quad$ 2-amino-(5S,8R)-5,6,7,8-tetrahydro-8,9,9-trimethyl-5,8methanoquinazoline $\quad 7,{ }^{[24]} \mathrm{Ni}\left(\mathrm{PPh}_{3}\right)_{2} \mathrm{Cl}_{2},{ }^{[25]} \mathrm{Mo}(\mathrm{CO})_{4}\left(\eta^{4} \text {-norbornadiene }\right)^{[26]}$ and $\left[\mathrm{Ru}(\mathrm{dmb})_{2} \mathrm{Cl}_{2}\right]^{[27]}$ were prepared by literature procedures. Other reagents were obtained from commercial sources.

\section{4,4'-Di(tert-butyl)-2,2'-bipyrimidine 2}

A blue solution of $\mathrm{Ni}\left(\mathrm{PPh}_{3}\right)_{2} \mathrm{Cl}_{2}(750 \mathrm{mg}, 1.15 \mathrm{mmol})$ and $\mathrm{PPh}_{3}(601 \mathrm{mg}, 2.30 \mathrm{mmol})$ in dry dimethylformamide (20 mL) was treated with zinc dust (77 mg, $1.18 \mathrm{mmol})$ and stirred for 1 hour under a nitrogen atmosphere to generate a red solution. 2-Chloro-4(tertbutyl)pyrimidine (196 mg, $1.15 \mathrm{mmol}$ ) was added and the mixture stirred for 40 hours. The resulting mixture was poured into water $(35 \mathrm{~mL})$, boiled for 5 minutes and filtered. The filtrate was treated with ammonium hexafluorophosphate and the resultant white precipitate filtered off and dissolved in 2:1 acetonitrile/water $(15 \mathrm{~mL})$. Potassium cyanide (177 mg) (CAUTION!) was added to the solution which was then refluxed briefly, cooled and extracted with chloroform ( $3 \times 15 \mathrm{~mL}$ ). The extracts were combined and the chloroform removed in vacuo. The residue was dissolved in concentrated hydrochloric acid $(5 \mathrm{~mL})$, extracted with chloroform ( $3 \times 5 \mathrm{~mL}$ ) to remove triphenylphosphine, then made alkaline with aqueous $\mathrm{NaOH}$ (2 M) and re-extracted with chloroform (3 x $10 \mathrm{~mL})$. The final extracts were combined, whereupon evaporation of the solvent furnished the product as an off-white solid, which was recrystallized from ethanol/ether to give 2 (30 mg, 9.6\%), mp $114-115^{\circ} \mathrm{C}$. Mass spectrum: $\mathrm{M}^{+}$. calcd for $\mathrm{C}_{16} \mathrm{H}_{22} \mathrm{~N}_{4}$ : 270.1844. Found: 270.1840. $\delta_{\mathrm{H}}\left(\mathrm{CDCl}_{3}\right) 1.48\left(18 \mathrm{H}, \mathrm{s}, \mathrm{CH}_{3}\right), 7.45$ (2H, d, H5), 8.91 (2H, d, H6). $\delta_{\mathrm{C}}\left(\mathrm{CDCl}_{3}\right) 29.8$ (6C, $\left.\mathrm{CH}_{3}\right), 38.6\left(2 \mathrm{C}, \mathrm{C}\left(\mathrm{CH}_{3}\right) 3\right), 117.0$ (2C, C5), 156.1 (2C, C6), 163.1 (2C, C2), 179.2 (2C, C4).

\section{[4,4'- Di(tert-butyl)-2,2'-bipyrimidine]-tetracarbonyl-molybdenum 3}

A green solution of $\mathrm{Mo}(\mathrm{CO})_{4}\left(\mathrm{C}_{7} \mathrm{H}_{8}\right)(16.4 \mathrm{mg}, 0.037 \mathrm{mmol}$ or $32.8 \mathrm{mg}, 0.074 \mathrm{mmol})$ in THF (2 mL) was added dropwise to a stirred solution of 2 (10 mg, $0.037 \mathrm{mmol})$ in THF (5 $\mathrm{mL}$ ). The resultant deep red solution was stirred for 2 hours and a layer of petroleum ether was added. The solution was left to cool $\left(0^{\circ} \mathrm{C}\right)$ overnight to give $\mathbf{3}$ as a red microcrystalline solid (15 mg, 85\%). $\delta_{\mathrm{H}}\left(\mathrm{CDCl}_{3}\right) 1.48$ (18H, s, CH3), 7.45 (2H, d, H5), 9.08 (2H, d, H6). 
Bis-(4,4'-dimethyl-2,2'-bipyridine)-[4,4'-di(tert-butyl)-2,2'-bipyrimidine]-ruthenium(II)-bis(hexafluorophosphate) 4

4,4'-Di(tert-butyl)-2,2'-bipyrimidine 2 (18 $\mathrm{mg}, \quad 0.067 \mathrm{mmol})$ was reacted with $\mathrm{Ru}(\mathrm{dmb})_{2} \mathrm{Cl}_{2} .2 \mathrm{H}_{2} \mathrm{O}$ (34 mg, $0.059 \mathrm{mmol}$ ) in refluxing ethanol/water (3:1) for 5 hours. The mixture was cooled to room temperature, filtered to remove unreacted ligand and concentrated to dryness in vacuo. The resulting solid was dissolved in the minimum volume of water and the product precipitated by the addition of an aqueous solution of $\mathrm{NH}_{4} \mathrm{PF}_{6}$. It was recrystallized from acetonitrile/ether to give $\mathbf{4}$ as a red microcrystalline solid (36 mg, 52\%). FAB mass spectrum: calcd for $\left[\mathrm{C}_{40} \mathrm{H}_{46} \mathrm{~N}_{8} \mathrm{PF}_{6} \mathrm{Ru}\right]^{+}$: 885.2531. Found: 885.2535. $\delta_{\mathrm{H}}$ (CD $\left.{ }_{3} \mathrm{CN}\right) 1.48$ (18H, s, CH3), 2.59 (6H, s, dmb-CH3), 2.60 (6H, s, dmb-CH3), 7.29 (2H, d, dmb-H5), 7.34 (2H, d, dmb-H5). 7.56 (2H, d, dmb-H6), 7.57 (2H, d, H5), 7.74 (2H, d, dmbH6), 7.91 (2H, d, H6), $8.40(4 \mathrm{H}, \mathrm{s}, \mathrm{dmb}-\mathrm{H} 3) . \delta_{\mathrm{C}}\left(\mathrm{CD}_{3} \mathrm{CN}\right) 20.6$ (4C, dmb-CH $), 28.8$ (6C, CH3), 38.5 (2C, $\left.\underline{\mathrm{C}}\left(\mathrm{CH}_{3}\right)_{3}\right), 120.6$ (2C, C5), 125.2 (4C, dmb-C3), 128.6 (2C, dmb-C5), 128.8 (2C, dmb-C5), 150.8 (2C, dmb-C4), 150.9 (2C, dmb-C4), 151.1 (2C, dmb-C6), 151.6 (2C, dmb-C6), 156.8 (2C, dmb-C2), 157.0 (2C, dmb-C2), 158.7 (2C, C6), 162.7 (2C, C2), 179.6 (2C, C4).

\section{2-Chloro-(5S,8R)-5,6,7,8-tetrahydro-8,9,9-trimethyl-5,8-methanoquinazoline 8}

The amine 7 (1.05 g, $5.17 \mathrm{mmol}$ ) was added to concentrated hydrochloric acid (5 mL) cooled below $0^{\circ} \mathrm{C}$. Whilst maintaining the temperature below $-10^{\circ} \mathrm{C}$, an aqueous solution (2 $\mathrm{mL}$ ) of sodium nitrite $(0.46 \mathrm{~g}, 6.67 \mathrm{mmol})$ was added dropwise, and the resultant mixture left to stir at $-10^{\circ} \mathrm{C}$ for 1.5 hours. The mixture was then neutralised with $\mathrm{NaOH}$, allowed to warm to room temperature and extracted with chloroform $(3 \times 10 \mathrm{~mL})$. The combined extracts were concentrated (1-2 mL) in vacuo and absorbed onto a silica gel radial chromatography plate, which was eluted with chloroform to give two bands. The first band was collected, and the solvent removed in vacuo, to give $\mathbf{8}$ as a clear oil, which crystallized on standing (0.55 g, 48\%), mp 84-86 ${ }^{\circ} \mathrm{C}$. Mass spectrum: $\mathrm{M}^{+}$. calcd for $\mathrm{C}_{12} \mathrm{H}_{15} \mathrm{~N}_{2} \mathrm{Cl}$ : 222.0924. Found: 222.0924 . $\delta_{\mathrm{H}}\left(\mathrm{CDCl}_{3}\right) 0.60\left(3 \mathrm{H}, \mathrm{s}, \mathrm{syn}-9-\mathrm{CH}_{3}\right), 1.03(3 \mathrm{H}, \mathrm{s}$, anti-9-CH$), 1.17$ (1H, m, endo-H6), 1.25 (1H, m, endo-H7), 1.30 (3H, s, 8- $\mathrm{CH}_{3}$ ), 1.96 (1H, m, exo-H7), 2.19 (1H, m, exo-H6), 2.95 $(1 \mathrm{H}, \mathrm{d}, \mathrm{H} 5), 8.22(1 \mathrm{H}, \mathrm{s}, \mathrm{H} 4)$. The second band was collected and the solvent removed in vacuo to give 2-hydroxy-(5S,8R)-5,6,7,8-tetrahydro-8,9,9-trimethyl-5,8-methanoquinazoline 9 (0.32 g, 30\%), mp 213-215 ${ }^{\circ} \mathrm{C}$. Mass spectrum: $\mathrm{M}^{+}$. calcd for $\mathrm{C}_{12} \mathrm{H}_{16} \mathrm{~N}_{2} \mathrm{O}: 204.1263$.

Found: 204.1261. $\delta_{\mathrm{H}}\left(\mathrm{CDCl}_{3}\right) 0.70\left(3 \mathrm{H}, \mathrm{s}, \mathrm{syn}-9-\mathrm{CH}_{3}\right), 1.01(3 \mathrm{H}, \mathrm{s}$, anti-9-CH$), 1.16(1 \mathrm{H}$, 
m, endo-H6), 1.38 (1H, m, endo-H7), 1.24 (3H, s, 8-CH3), 1.90 (1H, m, exo-H7), 2.12 (1H, m, exo-H6), 2.78 (1H, d, H5), 7.44 (1H, s, H4). Compound 9 (0.30 g, 1.47 mmol) was refluxed in $\mathrm{POCl}_{3}$ to give additional 8 (185 $\left.\mathrm{mg}, 57 \%\right)$.

2,2'-Bi-(5S,8R)-5,6,7,8-tetrahydro-8,9,9-trimethyl-5,8-methanoquinazoline 5

A mixture of nickel chloride (0.32 g, $2.47 \mathrm{mmol}), \mathrm{PPh}_{3}(1.41 \mathrm{~g}, 5.38 \mathrm{mmol})$ and zinc dust $(0.13 \mathrm{~g}, 2.0 \mathrm{mmol})$, in dry dimethylformamide $(10 \mathrm{~mL})$, was stirred at $50^{\circ} \mathrm{C}$ under an argon atmosphere. After 1 hour, during which time the colour of the mixture changed from blue to green and finally to red $\left(\mathrm{Ni}^{0}\left(\mathrm{PPh}_{3}\right)_{2}\right)$, a solution of 8 (0.3 g, $\left.1.35 \mathrm{mmol}\right)$, in dimethylformamide (3 $\mathrm{mL}$ ), was added under an argon atmosphere, and the mixture left to stir at $50^{\circ} \mathrm{C}$ for a further 12 hours. The resultant brown mixture was poured into aqueous ammonia (50 ml, $2 \mathrm{M}$ ), filtered to remove the precipitate of triphenylphosphine oxide and the filtrate extracted with chloroform (3 x $40 \mathrm{~mL})$. The extracts were combined and the solvent removed in vacuo. The residue was redissolved in chloroform (1-2 mL) and absorbed onto a silica gel radial chromatography plate. Excess triphenylphosphine was eluted with petroleum ether/ethyl acetate (1:1). Compound 5 was eluted with chloroform and the solvent removed in vacuo to give a white solid $(0.11 \mathrm{~g}, 44 \%), \mathrm{mp} 186-188^{\circ} \mathrm{C}$. Mass spectrum: $\mathrm{M}^{+}$. calcd for $\mathrm{C}_{24} \mathrm{H}_{30} \mathrm{~N}_{4}$ : 374.2471. Found: 374.2471. $\delta_{\mathrm{H}}\left(\mathrm{CDCl}_{3}\right) 0.63(6 \mathrm{H}, \mathrm{s}$, syn-9-CH3), 1.05 (6H, s, anti-9- $\left.\mathrm{CH}_{3}\right), 1.25$ (2H, m, endo-H6), 1.29 (2H, m, endo-H7), 1.47 (6H, s, 8- $\left.\mathrm{CH}_{3}\right), 1.95$ (2H, m, exo-H7), 2.23 (2H, m, exo-H6), 3.02 (2H, d, H5), $8.64(2 \mathrm{H}, \mathrm{s}, \mathrm{H} 4) . \delta_{\mathrm{H}}\left(\mathrm{CD}_{3} \mathrm{CN}\right) 0.66(6 \mathrm{H}$, s, syn-9- $\left.\mathrm{CH}_{3}\right), 1.11$ (6H, s, anti-9- $\left.\mathrm{CH}_{3}\right), 1.18$ (2H, m, endo-H6), 1.35 (2H, m, endo-H7), 1.37 (6H, s, 8- $\left.\mathrm{CH}_{3}\right), 2.03$ (2H, m, exo-H7), 2.28 (2H, m, exo-H6), 3.11 (2H, d, H5), 8.58 (2H, s, H4). $\delta_{\mathrm{C}}\left(\mathrm{CD}_{3} \mathrm{CN}\right) 9.7$ (2C, 8- $\left.\mathrm{CH}_{3}\right), 18.5$ (2C, anti-9-CH3), 19.5 (2C, syn-9-CH3), 25.61 (2C, C6), 31.4 (2C, C7), 49.6 (2C, C5), 54.9 (2C, C9), 57.5 (2C, C8), 138.4 (2C, C4a), 147.4 (2C, C4), 162.0 (2C, C2), 179.6 (2C, C8a).

Dichloro-[2,2'-bi-(5S,8R)-5,6,7,8-tetrahydro-8,9,9-trimethyl-5,8-methanoquinazoline]palladium(II) 10

A hot solution of $\mathrm{PdCl}_{2}(5 \mathrm{mg})$ in $\mathrm{HCl}(3 \mathrm{~mL})$ was added dropwise to a hot solution of 5 (11 mg, $0.06 \mathrm{mmol})$ in methanol $(8 \mathrm{~mL})$. The resultant pale yellow precipitate of $\mathbf{1 0}$ was filtered off and air dried (9 mg, 26\%). Calcd for $\mathrm{C}_{24} \mathrm{H}_{30} \mathrm{~N}_{4} \mathrm{Cl}_{2} \mathrm{Pd} .1 .5 \mathrm{H}_{2} \mathrm{O} \mathrm{C}: 49.80, \mathrm{H}: 5.74$, N: 9.68. Found C: 50.21, H: 5.46, N: 9.76. 
[2,2'-Bi-(5S,8R)-5,6,7,8-tetrahydro-8,9,9-trimethyl-5,8-methanoquinazoline-N3,N3']tetracarbonyl-molybdenum 11

A solution of $\mathrm{Mo}(\mathrm{CO})_{4}\left(\mathrm{C}_{7} \mathrm{H}_{8}\right)(12 \mathrm{mg}, 0.04 \mathrm{mmol})$ in dry THF $(4 \mathrm{~mL})$ was added dropwise, with stirring, to a solution of $5(20 \mathrm{mg}, 0.05 \mathrm{mmol})$ in dry THF $(10 \mathrm{~mL})$. The solution rapidly became deep red and was stirred for 1 hour then diluted with petroleum ether $(6 \mathrm{~mL})$ and cooled $\left(0^{\circ} \mathrm{C}\right)$ overnight. The resultant red precipitate of $\mathbf{1 1}$ was filtered off and dried (10 mg, 43\%). Similarly, a two-fold excess of $\mathrm{Mo}(\mathrm{CO}){ }_{4}\left(\mathrm{C}_{7} \mathrm{H}_{8}\right)(24 \mathrm{mg}, 0.08 \mathrm{mmol})$ gave 11 (13 mg, 56\%). $\delta_{\mathrm{H}}\left(\mathrm{CDCl}_{3}\right) 0.65(6 \mathrm{H}, \mathrm{s}$, syn-9-CH3), $1.09(6 \mathrm{H}, \mathrm{s}$, anti-9-CH$), 1.27$ (2H, m, endo-H6), 1.42 (2H, m, endo-H7), 1.47 (6H, s, 8- $\left.\mathrm{CH}_{3}\right), 2.04$ (2H, m, exo-H7), 2.30 (2H, m, exo-H6), 3.07 (2H, d, H5), 8.81 (2H, s, H4).

Bis-(4,4'-dimethyl-2,2'-bipyridine)-[2,2'-bi-(5S,8R)-5,6,7,8-tetrahydro-8,9,9-trimethyl-5,8methanoquinazoline-N3,N3']-ruthenium(II)-bis-(hexafluorophosphate) 12

Ligand 5 (27.9 mg, $0.074 \mathrm{mmol})$ was reacted with $\mathrm{Ru}(\mathrm{dmb})_{2} \mathrm{Cl}_{2} \cdot 2 \mathrm{H}_{2} \mathrm{O}(39 \mathrm{mg}, 0.068$ mmol) as described above and the resultant solid recrystallized from acetonitrile/ether to give orange crystals of 12 (75mg, 91\%). Calcd for $\mathrm{C}_{52} \mathrm{H}_{60} \mathrm{~N}_{10} \mathrm{P}_{2} \mathrm{~F}_{12} \mathrm{Ru} .2 \mathrm{CH}_{3} \mathrm{CN}$ C: 51.36, H: 4.97, N: 11.52. Found C: 51.04, H: 5.06, N: 11.34. FAB mass spectrum: calcd for $\left[\mathrm{C}_{48} \mathrm{H}_{54} \mathrm{~N}_{8} \mathrm{PF}_{6} \mathrm{Ru}\right]^{+}$: 989.316. Found: 989.317. ${ }^{1} \mathrm{H}$ NMR showed the complex to exist as two diastereoisomers. $\delta_{\mathrm{H}}\left(\mathrm{CD}_{3} \mathrm{CN}\right) 0.36\left(6 \mathrm{H}, \mathrm{s}, \Delta-\mathrm{syn}-9-\mathrm{CH}_{3}\right), 0.77\left(6 \mathrm{H}, \mathrm{s}, \Lambda-s y n-9-\mathrm{CH}_{3}\right), 0.96$ (2H), 1.07 and 1.12 (2 x 6H, s, anti-9-CH3), $1.22(2 \mathrm{H}), 1.34(2 \mathrm{H}), 1.41$ and 1.45 (2 x 6H, s, 8$\mathrm{CH}_{3}$ ), 1.50 (2H), 2.12-2.31 (8H), 2.58 (24H, dmb-CH 3$), 2.98$ and 3.02 (2 x 2H, d, H5), 7.27 (8H, d, dmb-H5), 7.51 (2H, d, dmb-H6), 7.54 (4H, d, dmb-H6), 7.65 and 7.68 (2 x 2H, s, H4), 7.70 (2H, d, dmb-H6), $8.39(8 \mathrm{H}, \mathrm{s}, \mathrm{dmb}-\mathrm{H} 3) . \delta_{\mathrm{C}}\left(\mathrm{CD}_{3} \mathrm{CN}\right) \delta: 9.4$ and $9.5\left(8-\mathrm{CH}_{3}\right), 18.2$ and 18.3 (anti-9- $\mathrm{CH}_{3}$ ), 19.1 and 19.8 (syn-9- $\mathrm{CH}_{3}$ ), 20.6 (4C, dmb-CH $), 24.8$ and 24.9 (C6), 31.0 and 31.1 (C7), 49.7 and 49.8 (C5), 55.5 (2C, C9), 58.1 and 58.2 (C8), 125.16 (2C), 125.23 and 125.3 (2C, dmb-C3), 128.5 (2C), 128.6 and 128.7 (dmb-C5), 141.8 (2C, C4a), 148.7 and 149.0 (C4), 150.5, 150.6 (2C) and 150.64 (dmb-C4), 151.0, 151.1, 151.4 and 151.7 (dmb-C6), 156.85, 156.9 ${ }_{2}$ and 157.0 (2C, dmb-C2), 162.1 (2C, C2), 180.5 and 180.6 (C8a). 


\section{References}

1 P. J. Steel, Coord. Chem. Rev. 1990, 106, 227.

2 C. Kaes, A. Katz, M. W. Hosseini, Chem. Rev. 2000, 100, 3553.

3 A. L. Gavrilova, B. Bosnich, Chem. Rev. 2004, 104, 349.

4 (a) A. Juris, V. Balzani, F. Barigelletti, S. Campagna, P. Belser, A. von Zelewsky, Coord. Chem. Rev. 1988, 84, 85; (b) V. Balzani, A. Juris, M. Venturi, S. Campagna, S. Serroni, Chem. Rev. 1996, 96, 759.

5 D. D. Bly, M. G. Mellon, J. Org. Chem. 1962, 27, 2945.

6 (a) P. F. H. Schwab, F. Fleischer, J. Michl, J. Org. Chem. 2002, 67, 443; (b) G. Vlad, I.

T. Horvath, J. Org. Chem. 2002, 67, 6550.

$7 \quad$ E. V. Dose, L. J. Wilson, Inorg. Chem. 1978, 17, 2660.

8 J. Nasielski, A. Standaert, R. Nasielski-Hinkens, Synthetic Commun. 1991, 21, 901.

9 A. J. Downard, G. E. Honey, L. F. Phillips, P. J. Steel, Inorg. Chem. 1991, 30, 2260.

10 M. Iyoda, H. Otsuka, K. Sato, N. Nisato, M. Oda, Bull. Chem. Soc. Jpn. 1990, 63, 808.

11 P. J. Steel, E. C. Constable, J. Chem. Soc., Dalton Trans. 1990, 1389.

12 J. Watanabe, T. Saji, S. Aoyagui, Bull. Chem. Soc. Japan 1982, 55, 327.

13 D. L. Jameson, J. K. Blaho, K. T. Kruger, K. A. Goldsby, Inorg. Chem. 1989, 28, 4312. Mamula, Olimpia; von Zelewsky, Alex. Supramolecular coordination compounds with chiral pyridine and polypyridine ligands derived from terpenes. Coordination Chemistry Reviews (2003), 242(1-2), 87-95.

14 D. A. House, P. J. Steel, A. A. Watson, Aust. J. Chem. 1986, 39, 1525.

15 A. A. Watson, D. A. House, P. J. Steel, Aust. J. Chem. 1995, 48, 1549, and references therein.

16 C. M. Fitchett, P. J. Steel, New J. Chem. 2000, 24, 945.

17 S. Nagai, T. Ueda, S. Sugiura, A. Nagatsu, N. Murakami, J. Sakakibara, M. Fujita, Y. Hotta, J. Heterocycl. Chem. 1998, 35, 325.

18 A. A. Watson, D. A. House, P. J. Steel, J. Org. Chem. 1991, 56, 4072.

19 F. R. Keene, Coord. Chem. Rev. 1997, 166, 121.

20 F. R. Keene, Chem. Soc. Rev. 1998, 27, 185.

21 D. M. D'Alessandro, F. R. Keene, P. J. Steel, C. J. Sumby. Aust. J. Chem. 2003, 56, 657.

22 G. B. Bennett, R. B. Mason, L. J. Alden, J. B. Roach Jr, J. Med. Chem. 1978, 21, 623. 
23 A. W. Bishop, W. Sinclair, L. Claissen, Liebigs Ann. Chem. 1984, 281, 314.

24 S. Nagai, T. Ueda, A. Nagatsu, K. Nakaoka, N. Murakami, J. Sakakibara, M. Fujita, Y. Hotta, J. Heterocycl. Chem. 1998, 35, 329.

25 J. Venanzi, J. Am. Chem. Soc. 1958, 80, 719.

26 M. A. Bennett, L. Pratt, G. J. Wilkinson, J. Chem. Soc. 1961, 2037.

27 P. A. Mabrouk, M. S. Wrighton, Inorg. Chem. 1986, 25, 526. 


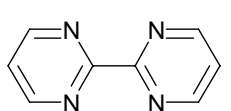

(1)

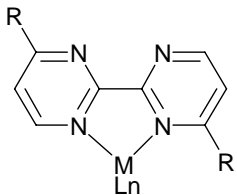

(B)

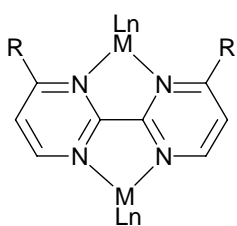

(D)

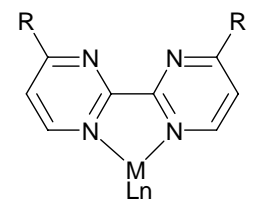

(A)

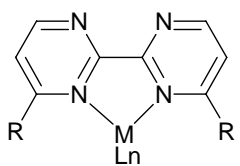

(C)

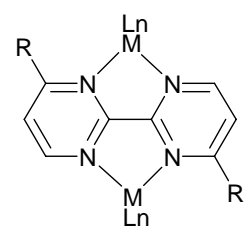

(E)

Fig. 1. Structure 2,2'-bipyrimidine and possible coordination modes for mononuclear (A-C) and homobinuclear (D,E) complexes of 4,4'-disubstituted derivatives. 


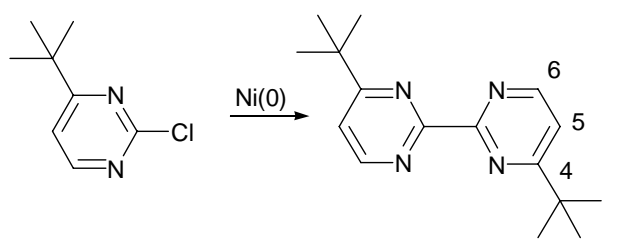

(2)<smiles></smiles>

(3) $\mathrm{ML}_{\mathrm{n}}=\mathrm{Mo}(\mathrm{CO})_{4}$

(4) $M L_{n}=R u(d m b)_{2}{ }^{2+}$

Scheme 1

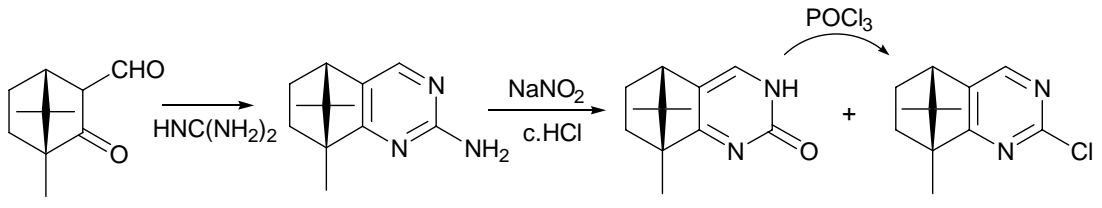

(6)

(7)

(8)

(9)

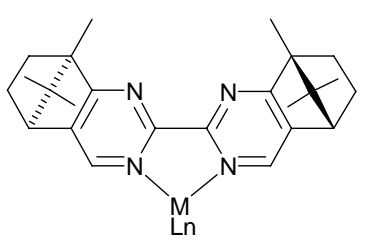

(10) $\mathrm{ML}_{\mathrm{n}}=\mathrm{PdCl}_{2}$

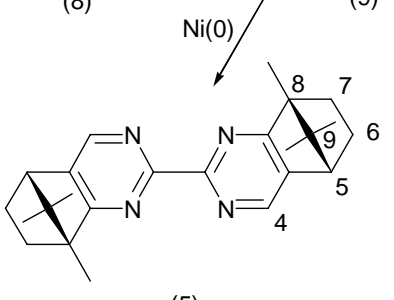

(11) $\mathrm{ML}_{\mathrm{n}}=\mathrm{Mo}(\mathrm{CO})$

(12) $M L_{n}=R u(d m b)_{2}{ }^{2+}$

\section{Scheme 2}

